\title{
The lifespan of semiconductor patents by assignee and patent characteristics
}

\author{
Shu-Hao Chang ${ }^{\mathrm{a}}$ and Chin-Yuan Fan \\ Science and Technology Policy Research and Information Center, National Applied Research Laboratories, Taipei \\ 106, Taiwan
}

\begin{abstract}
Evaluating the values of patents is critical for both managers and investors. Patent maintenance time is an ideal proxy indicator for evaluating commercial patent value. This study investigated the survival rates of patents in the semiconductor industry by using a survival analysis and incorporated a predictive model for patent maintenance times. The technical characteristics of the patents, the assignee factors, and the statuses of the patents were used as the predictive factors for patent maintenance time. The results revealed a small entity size and the number of assignees are the risk factors that increase the likelihood of the maintenance time of a patent decreasing. The litigation status of a patent and the number of its international patent classifications, claims, forward citations, and assignments were determined to be the protection factors that raise the likelihood of its maintenance time extending. Additionally, substantial differences were noted between small entities and nonsmall entities and between being litigated and not in their effects on the survival rates of patents. This study examined the factors that affect the survival rates of patents and provides a reference for the managers and investors of intellectual property rights to use when assessing technical and commercial patent values.
\end{abstract}

\section{Introduction}

Since the arrival of the knowledge economy, the governments of advanced countries have paid considerable attention to the economic benefits achieved by owning intellectual properties, which have become one of the key factors of economic development. Patents are a crucial carrier and form of intellectual properties. Therefore, numerous multinational research institutes and companies have tried to measure patent values by using certain tools or methods. Particularly, the method of determining patent values by using the data in patent documents continues to be discussed among scholars [1-4].

Determining patent values is critical for managers, investors, and developers. The most notable indicators of patent values are forward citations [2, 5, 6] and patent maintenance time [7-9]. However, forward citations only indicate that a patent has been cited by another patent. In other words, by measuring the influence of the patent on the technical development of subsequent patents, forward citations indicate the technical value of patents but not the commercial value. Bessen [7] maintained that the correlation between forward citations and commercial patent value is low; in other words,

\footnotetext{
${ }^{\mathrm{a}}$ Corresponding author : shchang@ narlabs.org.tw
} 
although a patent may exhibit high technical value, it may not be successfully converted to company profit. The patent maintenance time indicates the validity time of patents. To maintain the validity of their patent claims, patent assignees must not only pay official patent maintenance fees, but also invest a considerable amount of labor force and effort to manage their patents. Therefore, the existence of commercial patent value is typically indicated by the intentions of assignees to continue their payments to maintain their claims [10]. Accordingly, patent maintenance time represents the commercial value of patents. Although no consensus has been formed on how to measure commercial patent value, we maintained that estimating patent maintenance time is a practical means for doing so.

In this study, patent maintenance time was incorporated as the proxy variable for patent values, and a predictive model for patent maintenance time was established on the basis of patent characteristics. Previous studies have reported that the maintenance time of a patent varies considerably according to its technical domains [11]. Therefore, semiconductor technology was selected as the domain of this study to avoid the variability in patent maintenance times. There were two reasons for selecting the semiconductor technology as the domain of this study. First, following the arrival of the Internet of Things, the demand for various sensors and low-power, low-cost semiconductor chips has rapidly increased, and the global semiconductor industry is expected to continue to grow. Second, the patent competition among semiconductor manufacturers is considerably intense; these manufacturers have sought intellectual property protection strategies that involve maximizing their patent portfolios to increase their own competitive advantages $[12,13]$. Therefore, semiconductor technology, which is a vital domain for patents, was selected as the target of this study.

This study focused on patent maintenance time to examine its related factors and assess commercial patent value. Recent empirical studies have employed identification models to explore the factors associated with patent maintenance time [9, 14, 15], such as maintenance fees [14-16], technological domains [9, 15, 17], the extents of forward citations [2], and the number of claims [9]. The decision to maintain a patent is typically formulated by the patent assignee. However, few studies have addressed the assignee factors [14]. Practically, patent assignees forfeit their patents for reasons related to the sizes of the assignee companies and their deliberate arrangements in addition to the patent skills of the assignees themselves. Therefore, the sizes and types of assignees were employed in this study to compare academic patents with industrial patents.

Whether patents are assigned and litigated affects their maintenance time. Studies have reported that assigned and litigated patents are more valuable than normal patents [18, 19]. Therefore, these characteristics of patents were included in the model to verify their influence on patent maintenance time. A survival analysis was conducted on patent maintenance time because the patent data in this study were censored data. Patent maintenance fees must be submitted by no later than the 4th, 8th, and 12 th years after the date a patent was approved; in other words, each patent can be maintained for a maximum of three times until its 20 -year official maintenance time expires. The time interval applied in this study was 12 years. Therefore, whether a patent that was maintained for 12 full years was continued or forfeited was not determined by this study. The information from censored data is incomplete and is typically right censored data. Therefore, conventional regression analysis was inapplicable for this study [20]. Finally, although survival analysis has been applied in previous studies to investigate patent maintenance time [21-24], nearly no study has implemented a survival analysis to explore the characteristics of patents during their approval processes and their statuses after their approval, such as of being assigned and litigated, as well as considered the sizes and types of assignees. This study incorporated a survival analysis to such an effect.

\section{Research method}

\subsection{Patent data sources}

This study incorporated the database of the United States Patent and Trademark Office (USPTO). This is a representative patent database because inventors typically simultaneously register their patents in 
the United States in addition to other countries [25], and US systems are considered widely representative of assignee size. On the definition of the semiconductor technology, the World Intellectual Property Organization (WIPO) established an international patent classification (IPC)technology concordance table in accordance with the technological domains that patents belong to [26]. The technological domains are divided into a total of 35 types; particularly, the semiconductor technology corresponds to the IPC code of H01L. The maintenance fees of a patent must be submitted by no later than the 4th, 8 th, and 12th years after the date the patent was approved; in the period from the 12th year (the third fee submission date) to the 20th year (the year the official patent maintenance time expires), no more maintenance fees are required to be submitted. Therefore, the first 12 years of patent maintenance (2002-2014) were selected as the primary time interval for analysis. In 2014, the third maintenance results of the patents approved in 2002 could be thoroughly examined. A total of 10,148 patents were investigated in this study.

\subsection{Survival function estimation methods}

For a duration analysis, the duration function is defined as follows. Let $f(t)$ be a continuous probability density of a random available $T$, where $t$ is a realization of $T$ as the representation of the maintenance. The corresponding cumulative distribution is provided as $F(t)=\int_{0}^{t} f(s) d s=\operatorname{Pr}(T \leq$ $t$ ). The probability that the spell is of the length of $t$ can then be expressed as $S(t)=\int_{t}^{\infty} f(s) d s=$ $1-F(t)=\operatorname{Pr}(T \geq t)$. $\mathrm{S}(\mathrm{t})$ is the survival function. A survival density function can be defined as follows: $s(t)=S^{\prime}(t)=\frac{d}{d t} S(t)=\frac{d}{d t}[1-F(t)]=-f(t)$. Because the life duration lasts until $t$, the probability that it will be terminated at the next time change $(\Delta)$ can be defined as Prob $(t \leq T \leq t+\Delta$ I $T \geq t$ ), which can be characterized by a hazard function:

$$
h(t)=\lim _{\Delta t \rightarrow 0} \frac{\operatorname{Pr}(t \leq T \leq t+\Delta t \mid T \geq t)}{\Delta t}=\lim _{\Delta t \rightarrow 0} \frac{\mathrm{F}(\mathrm{t}+\Delta t)-\mathrm{F}(\mathrm{t})}{\Delta t S(t)}=\frac{\mathrm{f}(\mathrm{t})}{S(t)}
$$

The hazard function specifies the instantaneous rate of completion of a duration at $T=t$, conditional upon survival until time $t$.

There are three approaches to model survival times: nonparametric, parametric and semiparametric. The Kaplan-Meier estimate was employed to clarify the differences among the various groups of patents in their maintenance times. The Kaplan-Meier estimate is a nonparametric estimation method used to calculate the differences among various groups on a survival curve. The formula of the Kaplan-Meier estimate is expressed as follows: $\hat{S}_{K M}(t)=\prod_{t_{(i)<t}} \frac{n\left(t_{i}\right)-d\left(t_{i}\right)}{n\left(t_{i}\right)}$, where $n\left(t_{i}\right)$ represents the number of patents still being maintained during the time $t_{(i)}$ and $d\left(t_{i}\right)$ represents the number of patents no longer maintained during $t_{(i)}$. To determine the factors that affect patent maintenance, this study implemented the Cox proportional hazard model, which is a semiparametric maintenance model. The Cox model does not require a particular probability distribution to represent survival times. The Cox model is as follows:

$$
h(t)=h_{0}(t) \cdot \operatorname{Exp}\left(\beta_{1} x_{1}+\beta_{2} x_{2}+\cdots+\beta_{k} x_{k}\right)
$$

where $h_{0}(t)$ is the baseline hazard function and $\beta_{1}, \cdots \beta_{k}$ are parameters to be estimated. The remainder of this section further describes the explanatory variables included in the Cox proportional hazard model.

\subsection{Explanatory variables}

\subsubsection{Sizes of assignees}


Small assignees are typically divided into three types, namely small companies, individuals, and nonprofit organizations. Studies have indicated that the commercial value of the patents owned by small assignees is generally lower than that of the patents owned by large assignees [7]. Consequently, the long-term maintenance values of the patents owned by small assignees are lower than those of the patents owned by large assignees. Furthermore, because maintaining patents is expensive, small assignees are less capable of affording patent maintenance fees than large assignees are. However, because the patent maintenance fees paid by small assignees are only approximately half of those of large assignees, the payment rates of small assignees are lower than those of large assignees . Consequently, as indicated in some studies, the patent maintenance time of small assignees in the Canadian Intellectual Property Office is longer than that of large assignees [22]. This reveals that the effect of the sizes of assignees on the validity time of patents is undetermined. Therefore, the sizes of patents were differentiated in the aforementioned Cox model to verify their effects on patent maintenance time.

\subsubsection{Types of assignees}

In the 1980s, the US government passed the Bayh-Dole Act to change the policies that had attributed the research results generated by government-sponsored universities as state-owned, thus causing a considerable increase in patent applications by university authorities [27, 28]. However, university patent assignees differ from enterprise patent assignees regarding their motivations to apply for patents [29], the problems facing them in the patent application process [27], and their means to acquire research and development ( $R \& D$ ) funds [30]. Therefore, the types of patent assignees were differentiated in the Cox model to clarify the difference between academic assignees and nonacademic assignees in their effects on patent maintenance time.

\subsubsection{Number of patent assignments}

Bessen [7] reported that the validity time for the patents owned by small assignees is shorter than that of the patents owned by large assignees. This is not only because the commercial value of the patents owned by small assignees is lower than that of the patents owned by large assignees, but also possibly because the valuable patents owned by small assignees are acquired by large firms. In other words, a patent with a higher commercial value is assigned more frequently and is valid for a longer duration. Therefore, the number of patent assignments was included in the Cox model.

\subsubsection{Litigation}

According to previous studies, commercial patent value is indicated by the threat of litigation; that is, the higher the threat of litigation, the greater the monetary value of the patent [31]. Specifically, patents that bear the threat of litigation or have been litigated exhibit high commercial patent value, and assignees are typically strongly inclined to continue paying maintenance fees to protect these patents. Because the research on the effect of litigation on the validity of patents is lacking, litigation was included in the Cox model.

\subsubsection{Number of patent assignees and inventors}

According to previous studies, technical cooperation effectively improves scientific research efficiency and competence $[32,33]$. Technical cooperation is divided into numerous types, such as $\mathrm{R}$ \& D cooperation, collaborative design, and cooperative production. Patent codevelopment and cooperation, which can be regarded as specific technical cooperative behaviors [34], improve the future citation rates of patents and their influence on subsequent technological development. The size of a patent inventor team can be regarded as the extent of resource investment and commitment 
toward the patent by an enterprise [35] as well as the intention of the enterprise to increase its resource input to maintain the validity of the patent.

\subsubsection{Backward citations}

Backward citations are applied to scientific publications and other patents. Particularly, scientific publications are regarded as nonpatent references (NPRs) and indicate the connectivity between the patents and basic science [36]. A larger backward citation indicates a larger amount of technology and knowledge cited by a patent and reflects the scope of knowledge and recognition by inventors or patent examiners on the patent. Therefore, a larger backward citation indicates when a patent is more valuable [37] and will likely be valid for a longer time.

\subsubsection{Forward citations}

The patents that are cited by other patents are referred to as forward citations [3]. When a patent is cited by other patents, the patent has contributed to further technological development. Forward citations are prevalently used as an index for technical patent value; a larger forward citation indicates a higher technical patent value [5, 6, 37]. Suh [3] incorporated forward citations to examine the relationship between forward patent citation networks and patent prices. This relationship reveals that forward citations do affect technical patent value, which in turn define patent maintenance time.

\subsubsection{Number of IPCs}

The number of IPCs represents the number of types of registration of a patent and its interdisciplinary characteristic. The number of IPCs implies the technical range of the application of a patent and indicates the scope of the patent [6]. Lerner [38] measured the market values of biotechnological companies by using the number of IPCs. Lerner [38] indicated that the number of IPCs represents the scope of inventions patented by a company and is highly correlated with the market value of the company. Therefore, the number of IPCs was incorporated in the Cox model to explore its relationship with patent maintenance time.

\subsubsection{Number of claims}

The technical scope and breadth of patent protection can be measured through the number of claims [38], which refers to the number of technical items claimed in a patent. The larger the number of claims in a patent is, the broader the patent is indicated to be. The number of claims affects not only patent values, but also patent maintenance time [24].

\section{Data analysis}

\subsection{Descriptive statistics}

Table 1. Descriptive statistics.

\begin{tabular}{|c|c|c|c|}
\hline Variables & Description & Mean & SD \\
\hline Time to expiration & Lifespan of the patent & 15.57 & 5.58 \\
\hline $\begin{array}{l}\text { Ratio of expired patents } \\
(\%) \\
\text { Technical characteristic of } \\
\text { the patent }\end{array}$ & $\begin{array}{l}\text { Dummy that equals } 1 \text { if the patent has expired } \\
\text { and } 0 \text { otherwise. }\end{array}$ & 41.71 & - \\
\hline Number of inventors & Number of inventors of the patent & 2.55 & 1.74 \\
\hline
\end{tabular}




\begin{tabular}{|c|c|c|c|}
\hline Number of assignees & Number of assignees of the patent & 1.01 & 0.28 \\
\hline $\begin{array}{l}\text { Number of backward } \\
\text { citations }\end{array}$ & Number of backward citations of the patent & 12.49 & 15.47 \\
\hline Number of IPCs & Number of IPCs of the patent & 5.37 & 2.58 \\
\hline Number of NPRs & Number of nonpatent references of the patent & 1.68 & 6.25 \\
\hline $\begin{array}{l}\text { Number of claims } \\
\text { Assignee factor }\end{array}$ & Number of claims of the patent & 16.67 & 12.38 \\
\hline Ratio of small entities (\%) & $\begin{array}{l}\text { Dummy that equals } 1 \text { if the assignee is a small } \\
\text { entity and } 0 \text { otherwise. }\end{array}$ & 4.73 & - \\
\hline $\begin{array}{l}\text { Ratio of university patents } \\
(\%)\end{array}$ & $\begin{array}{l}\text { Dummy that equals } 1 \text { if the patent is an } \\
\text { academic patent and } 0 \text { otherwise. }\end{array}$ & 1.01 & - \\
\hline \multicolumn{4}{|l|}{ Patent status } \\
\hline Ratio of litigation (\%) & $\begin{array}{l}\text { Dummy that equals } 1 \text { if the patent has been } \\
\text { litigated and } 0 \text { otherwise. }\end{array}$ & 0.36 & - \\
\hline $\begin{array}{l}\text { Number of forward } \\
\text { citations }\end{array}$ & Number of forward citations of the patent & 13.63 & 23.26 \\
\hline Number of assignments & Number of assignments of the patent & 1.53 & 1.55 \\
\hline
\end{tabular}

The descriptive statistics results are listed in Table 1 . In the selected period, $41.71 \%$ of patents had already expired because of unpaid annual renewal fees. Regarding the size of patent assignees, $4.73 \%$ of patent assignees were small entities. For the types of patents, $0.36 \%$ of the patents were litigated, and $1.01 \%$ were academic. The results showed that the average expired period of patents was 15.57 years. The descriptive statistics of patent characteristics is also shown in Table 1.

\subsection{Cox proportional hazard model}

Table 2 shows the results of the Cox proportional hazard model. The following variables were correlated with patent survival: small entity, litigation, university patents, number of inventors, number of assignees, number of forward citations and backward citations of patents, number of IPCs, number of NPRs, number of claims, and number of assignments.

Table 2. Cox proportional hazard results.

\begin{tabular}{lcc}
\hline Explanatory variables & Hazard ratio: 95\% confidence intervals & Significance \\
\hline Number of inventors & $1.006(0.988-1.024)$ & 0.510 \\
Number of assignees & $1.108(1.001-1.126)$ & 0.048 \\
Number of backward citations & $1.000(0.998-1.002)$ & 0.909 \\
Number of IPCs & $0.980(0.968-0.992)$ & 0.001 \\
Number of NPRs & $1.001(0.995-1.007)$ & 0.798 \\
Number of claims & $0.995(0.992-0.997)$ & 0.000 \\
Small entity & $2.588(2.300-2.914)$ & 0.000 \\
University patents & $0.834(0.633-1.097)$ & 0.194 \\
Litigation & $0.233(0.075-0.722)$ & 0.012 \\
Number of forward citations & $0.991(0.989-0.993)$ & 0.000 \\
Number of assignments & $0.850(0.828-0.872)$ & 0.000 \\
Log likelihood & 76329.473 & \\
Chi-squared & $573.808 * * *$ & \\
\hline
\end{tabular}

Note: $* * *$ indicates significance at the $1 \%$ level; the total number of observations equals 10,148 , of which 4,233 were right-censored.

As the chi-squared value demonstrated, the regression model was significant at the $1 \%$ level. The results showed that several patent characteristics have significant effects on the patent maintenance time, such as assignee size (being a small entity), number of assignees, number of IPCs, and number 
of claims. Additionally, some of the processing status and development factors of the patents, such as the number of forward citations and assignments and whether the patents in question had been litigated, affected their maintenance time. When the hazard ratio of a factor was higher than 1, it indicated that the factor was a risk factor. As shown in Table 2, small entities and the number of assignees were risk factors, indicating that when the assignees were small entities and the number of assignees was high, the likelihood that the maintenance time of a patent was shortened was increased. The litigation statuses and the numbers of forward citations, IPCs, claims, and assignments were protection factors; when a patent was litigated, and the numbers of its assignments, forward citations, IPCs, and claims were high, its maintenance time was likely to extend. For example, when the other factors remained constant, each additional assignment reduced the survival-risk probability of a patent by $15 \%(1-0.850=0.150)$.

\subsection{Kaplan-Meier estimate}

The factors "small entity" and "litigation" reached the level of significance as shown in Table 2 and were both dummy variables. Therefore, the Kaplan-Meier estimate was employed to verify the survival rate of each group of patents, and the Log-Rank, Wilcoxon, and Tarone-Ware tests were conducted to determine the differences among the groups regarding their survival rates. The LogRank test is a statistical measurement method designed to compare two survival curves, in which the data is right skewed and censored. The Wilcoxon and Tarone-Ware methods are alternative measurement methods for comparing survival curves and were also significant. The results of these measurements are shown in Table 3.

Table 3. Tests for comparing survival curves among groups.

\begin{tabular}{|l|c|c|c|}
\hline \multirow{2}{*}{ Variables } & \multicolumn{3}{|c|}{$x^{2}$ value } \\
\cline { 2 - 4 } & Log-Rank & Wilcoxon & Tarone-Ware \\
\hline Small entity & $331.307 * * *$ & $347.771 * * *$ & $340.235^{* * *}$ \\
\hline Litigation & $15.177 * * *$ & $14.961 * * *$ & $15.103 * * *$ \\
\hline
\end{tabular}

The Kaplan-Meier estimates of survival were graphed on the basis of the size of entity and litigation. Figure 1 presents the patent assignees that were nonsmall entities and survived longer than those that were small entities in the semiconductor field.

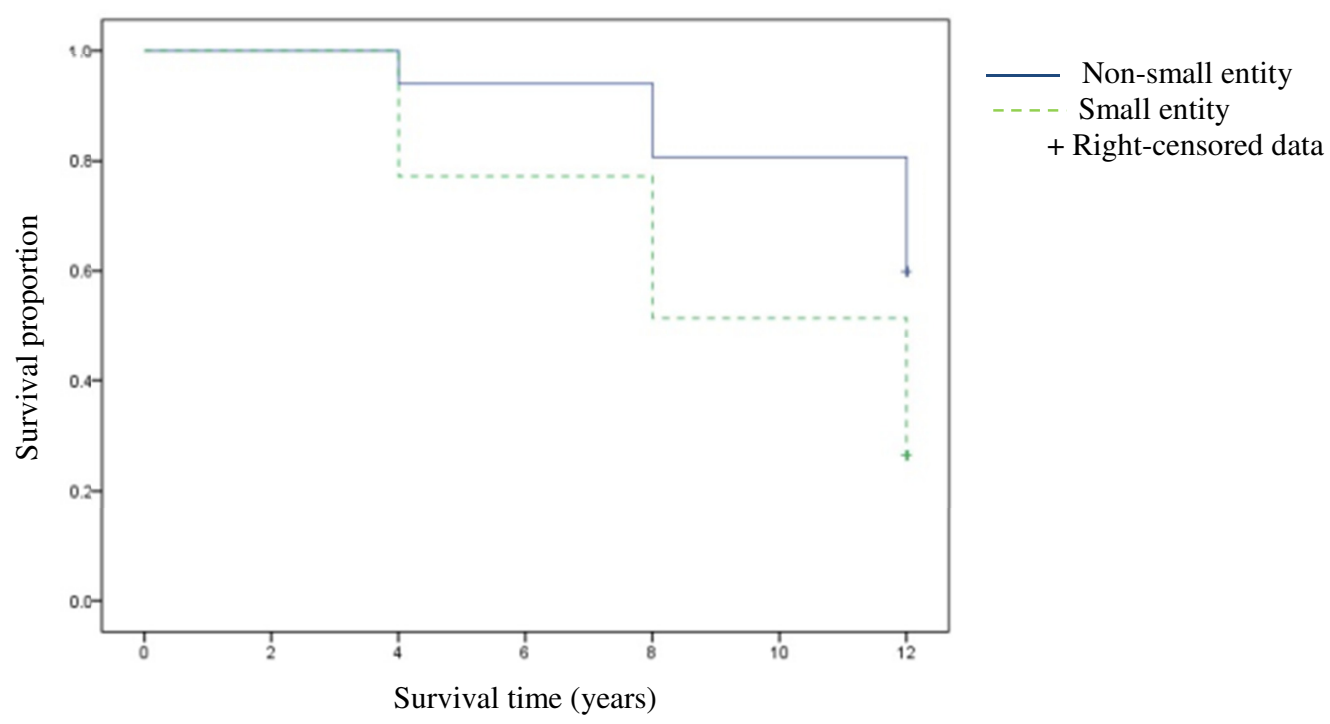

Figure 1. Kaplan-Meier survival estimates, by small entity. 
As shown in Figure 1, after the first patent maintenance fees were paid (4 years), the survival rate of the small-entity patents was approximately $77 \%$, and that of the nonsmall-entity patents was $94 \%$; after the second patent maintenance fees were paid ( 8 years), the survival rate of the small-entity patents decreased to approximately $51 \%$, and that of the nonsmall-entity patents was $81 \%$; after the third patent maintenance fees were paid (12 years), the survival rate of the small-entity patents was approximately $27 \%$, and that of the nonsmall-entity patents was $60 \%$. Figure 2 illustrates the comparison of the litigated and nonlitigated patents on their survival rates. The results indicate that litigated patents have higher survival rates than nonlitigated patents do.

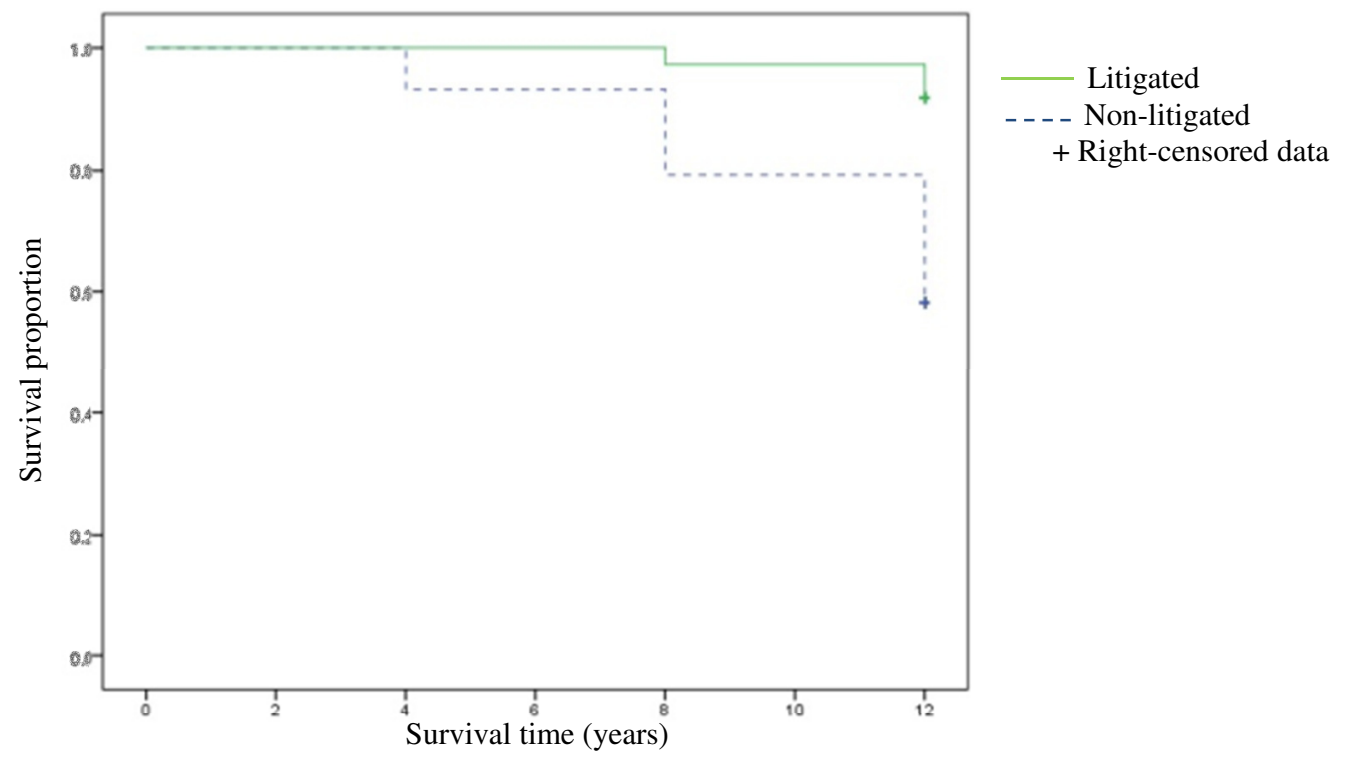

Figure 2. Kaplan-Meier survival estimates, by litigation.

According to Figure 2, after the first patent maintenance fees were paid (4 years), nearly all of the litigated patents remained intact, and the survival rate of the nonlitigated patents was 93\%; after the second patent maintenance fees were paid (8 years), the survival rate of the litigated patents decreased to approximately $97 \%$, and that of the nonlitigated patents was $79 \%$; after the third patent maintenance fees were paid (12 years), the survival rate of the litigated patents was approximately $92 \%$, and that of the nonlitigated patents was $58 \%$. Accordingly, after the third patent maintenance fees were paid, a sizable difference was observed between the litigated patents and the nonlitigated patents on their survival rates; more than $90 \%$ of the litigated patents remained valid until the 12 th year.

\section{General discussion}

This study investigated the factors that affect the validity time of patents by using a survival analysis. The factors considered in this study were the technical characteristics of patents, comprising the number of IPCs, claims, and backward citations, as well as assignee factors, comprising the sizes and types (academic or nonacademic) of assignees. In addition, this study examined the subsequent development and statuses of the patents, such as their litigation statuses and the numbers of their forward citations and assignments. The differences among the patents of different characteristics of their survival rates were also compared.

Regarding the technical characteristics of patents and the assignee factors, according to the analysis results, small entity sizes and the number of assignees were risk factors; in other words, when the assignees of a patent were small companies and their number was high, the maintenance time of the patent was substantially likely to decrease. This revealed the large-entity-dominant, monopolized, and concentrated characteristics of the semiconductor industry. Previous studies have addressed the 
semiconductor industry as a capital-intensive industry in which equipment costs account for more than $70 \%$ of the capital investment in semiconductor test facilities [39]. For patent skills, this study further verified that the large manufacturing companies were more capable of continuing maintaining their patents than the small companies were, and the patents owned by the large companies were typically more worthy of protecting than those of the small companies were. Additionally, because the semiconductor industry is a technology-intensive industry [40], its high-end technology is commonly controlled by specific companies that hold a considerable monopoly on the industry. Consequently, the technology development alliances in the global semiconductor industry have decreased yearly [41], and research joint ventures have typically been replaced by mergers for companies to acquire necessary technology [42]. Therefore, patents that are valuable and worth protecting have typically been concentrated on one single patent assignee (company).

Some of the technical characteristics examined in this study, namely the numbers of IPCs and claims, increased the probability of extending patent maintenance time. This corresponded to the findings in previous studies. Patent breadth is a critical determining factor for the effectiveness of patent protection [6]. The technical scope and breadth of patent protection can be analyzed by using the numbers of claims and IPCs [39]. Patent applicants can increase their number of claims by writing patent documents and thereby expanding the technical breadth of their patents [43]. Patent assignees can redefine the domain of patents by increasing the number of claims, thus expanding the rights requirements of the patent breadth under certain conditions [7]. The number of claims can be used to explain the operational scope of a patent [44]. Because patents with large numbers of claims are regarded as considerably valuable, they may be frequently litigated [44, 45]. IPCs belong to the technical scope of patent protection (Lerner, 1994); large technical scopes form broad potential values for patents.

No significant differences were observed between the academic patents and the nonacademic patents for their survival rates. This was possibly because the R \& D of the semiconductor industry was still concentrated in enterprises. Finally, the subsequent development and statuses of the patents, particularly litigation and the numbers of forward citations and assignments, were observed to significantly affect the survival rates of the patents. Litigation statuses and the number of assignments indicated the commercial value of the patents, and the number of forward citations revealed the technical value of the patents. The patents with higher commercial and technical values were confirmed to be more likely to maintain or extend their validity time.

\section{Practical implications}

This study examined whether significant differences existed among the patent assignees of different sizes and between the litigated patents and the nonlitigated patents regarding their effects on patent maintenance time. In addition, the survival rates of the patents were separately investigated. The results provide a reference to the Taiwanese government for improving patent maintenance fees. For the existing patent pricing systems, the USPTO currently only varies patent maintenance costs in accordance with the sizes of assignee entities and the time points of patent maintenance. This study addressed a substantial difference between the litigated patents and the nonlitigated patents in their survival rates. Therefore, the prices on these patents can be varied according to different time points of maintenance in the future. In addition, the numbers of IPCs, claims, forward citations, and assignments can be employed as the adjustment factors for maintenance fees.

Patent maintenance time is still an ideal proxy indicator for commercial patent value [7]. According to the patent survival rate estimation results from the survival analysis in this study, each patent exhibited a separate survival rate. A patent value estimation model was established, and the predictive indices for the values and maintenance time of a semiconductor patent, comprising the sizes of its assignees, its litigation statuses, and the numbers of its IPCs, claims, forward citations, and assignments, were incorporated in the analysis. In the future, the values of specific patents should be predicted by using their technical characteristics, assignee factors, and subsequent statuses. The prediction results provide a reference to the managers and investors of intellectual property rights. 


\section{Limitations and future research directions}

Numerous limitations were encountered in this study. First, the patent data employed in this study were from the USPTO database. Although the database is one of the most reliable patent databases worldwide, some semiconductor patents were not registered in the USPTO. This was a limitation in the data source. Second, the USPTO provides preferential fees to microentities in addition to those of general and small entities. Although the microentity fees constitute a considerably small proportion of all the fees provided, the maintenance time and technical characteristics of microentities should be independently discussed to determine whether they differ significantly from those of small entities. Third, because the process of patent maintenance is extremely complex and involves numerous factors, we suggest that future researchers integrate related variables. For example, they can include patent application experience or patent family as one variable. Fourth, the technical characteristics of the patents, assignee factors, and the patent statuses were applied as the determining factors for the survival rates of the patents. However, the decisions to maintain patents are frequently influenced by external factors such as the speed of technical changes, company strategies, and market environments. In this study, patent characteristics were explored from the perspective of the patents themselves; for the assignee factors, only the sizes of the assignees and whether certain patents were academic were considered, but the operations and strategies of the companies were not incorporated in the analysis. If the funds and human resources in future studies are sufficient, then future studies should implement company-level variables, such as the annual revenues and R \& D costs of companies to increase the scope of the research and the validity of the survival model.

\section{References}

1. M. Reitzig, Res. Policy 32, 13-26 (2003)

2. T. Schubert, Scientometrics, 88, 787-804 (2011)

3. J.H. Suh, Technol Anal Strateg, 27, 485-502 (2015)

4. G. Messinis, Scientometrics, 89, 813-833 (2011)

5. B. Hall, A. Jaffe, and M. Trajtenberg, Rand J Econ, 36, 16-38 (2005)

6. D. Harhoff, F Narin, F.M. Scherer, and K. Vopel, Res. Policy, 32, 1343-1363 (2003)

7. J. Bessen, Res. Policy, 37, 932-945 (2008)

8. C. Gronqvist, J. Technol. Transfer, 34, 159-168 (2009)

9. Y.J. Lee and J.D. Lee, Appl Econ, 40, 229-240 (2008)

10. H. Ernst, World Patent Information, 25, 233-242 (2003)

11. A. Pakes and M. Simpson, Brookings Pap. Eco. Ac., Special Issue, 331-401 (1989)

12. B.H. Hall and R.H. Ziedonis, Rand J Econ, 32, 101-128 (2001)

13. R.H. Ziedonis, Manage Sci, 50, 804-820 (2004)

14. J. Kim, Rev Ind Organ, 47, 195-218 (2015)

15. G. Zhang, X. Lv, and J. Zhou, China Econ Rev, 28, 37-54 (2014)

16. G. de Rassenfosse and B. van Pottelsberghe de la Potterie, J Econ Surv, 27, 696-716 (2013)

17. C.J. Serrano, Rand J Econ, 41, 686-708 (2010)

18. M.S. Meyer and P. Tang, Scientometrics, 70, 415-440 (2007)

19. N. Ziegler, F. Ruether, M.A. Bader, and O. Gassmann, J. Technol. Transfer, 38, 930-949 (2013)

20. F.J. Lawless, Statistical Models and Methods for Lifetime Data, Hoboken, NJ: John Wiley and Sons (2003)

21. D. Lewensohn, C. Dahlborg, J. Kowalski, and P. Lundin, Res Evaluat, 24, 197-212 (2015)

22. R. Nikzad, J World Intellect Prop, 14, 368-382 (2011)

23. R. Svensson, Appl Econ, 45, 1343-1358 (2013)

24. Y. Xie and D.E. Giles, Appl Econ, 43, 1375-1384 (2011)

25. S.D. Bass and L.A. Kurgan, Scientometrics, 82, 217-241 (2010)

26. WIPO, IPC-technology concordance table http://www.wipo.int/ipstats/en/statistics/technology_concordance.html (2016) 
27. N. Baldini, Res. Policy, 38, 1217-1224 (2009)

28. I. Feller and M. Feldman, J. Technol. Transfer, 35, 597-616 (2010)

29. N. Baldini, R. Grimaldi, and M. Sobrero, Scientometrics, 70, 333-354 (2007)

30. J.G. Thursby, A.W. Fuller, and M. Thursby, Res. Policy, 38, 14-25 (2009)

31. Z. Tekic and D. Kukolj, Res Technol Manage, 56, 18-25 (2013)

32. S. Lee and B. Bozeman, Soc Stud Sci, 35, 673-702 (2005)

33. F. Rijnsoever, L. Hessels, and R. Vandeberg, Res. Policy, 37, 1255-1266 (2008)

34. X.P. Lei, Z.Y. Zhao, X. Zhang, D.Z. Chen, M.H. Huang, J. Zheng, R.S. Liu, J. Zhang, and Y.H. Zhao, Scientometrics, 96, 427-441 (2013)

35. A. Breitzman and P. Thomas, Scientometrics, 103, 631-647 (2015)

36. Z.Y. Zhao and X.P. Lei, Curr Sci, 104, 714-720 (2013)

37. J. Suzuki, Res. Policy, 40, 986-1000 (2011)

38. J. Lerner, Rand J Econ, 25, 319-333 (1994)

39. C.F. Chien, J.N. Zheng, and Y.J. Lin, J Intell Manuf, 25, 899-911 (2014)

40. Y. Ho and H. Chiu, Asia Pac J Manage, 30, 1265-1283 (2013)

41. J.T. Macher, D.C. Mowery, and A.Di Minin, Calif Manage Rev, 50, 217-242 (2007)

42. K. Gugler and R. Siebert, Rev Econ Stat, 89, 645-659 (2007)

43. E. Sapsalis, B. van Pottlesberghe de la Potterie, and R. Navon, Res. Policy, 35, 1631-1645 (2006)

44. M. Reitzig, Res. Policy, 33, 939-957 (2004)

45. J. Lanjouw and M. Schankerman, Rand J Econ, 32, 129-151 (2001) 